Economics Consortium. The grant application signatories were JY, NS, KL, AF, and Angela Clegg. The trial steering group and project group members were JY, AF, NS, Susan Ince, Laura Hibbs, Angela Clegg, Joy Warburton, Jackie Hansford, Anne McAdam, KM, KL, Jacqueline O'Reilly, and JG. The study research team included Linda Dobrzanska, Helen Wright, Emma Tanner, KM, and JG.

Contributors: See bmj.com

Funding: Health Foundation.

Competing interests: JY and JG have worked in the community hospital involved in this study.

Ethical approval: Bradford Hospitals NHS Foundation Trust research ethics committee

1 Young J, Donaldson K. Community hospitals and older people. Age Ageing 2001; 30-S3:7-10.

Department of Health. The NHS plan: a plan for investment, a plan for reform Cm 4818-I. London: Stationery Office, 2000.

3 Baker JE, Goldacre M, Gray JAM. Community hospitals in Oxfordshire: their effect on the use of specialist inpatient services. I Epidemiol Community Health 1986;40:117-20.
nir effect on the use of specis

4 Hine C, Wood VA, Taylor S, Charny M. Do community hospitals reduce the use of district general hospital inpatient beds? $J R$ Soc Med 1996;89:681-7
5 Cook PJ, Porter L. Community hospitals and district general hospital medical bed use by elderly people: a study of 342 general practitioner beds in Oxfordshire. Age Ageing 1998;27:357-61.

6 Department of Health. National service framework for older people. London: $\mathrm{DoH}, 2001$.

7 Hodkinson HM. Evaluation of a mental test score for assessment of mental impairment in the elderly. Age Ageing 1972;1:233-8.

8 Nouri FM, Lincoln NB. An extended activities of daily living scale for stroke patients. Clin Rehabil 1987;1:301-5.

9 Mahoney FI, Barthel DW. Functional evaluation: the Barthel index. Md State Med J 1965;14:61-5.

10 Collin C, Wade DT, Davies S, Horne V. The Barthel ADL index: a reliability study. Int Disabil Stud 1988;10:61-3.

11 Harwood RH, Ebrahim S. The validity, reliability and responsiveness of the Nottingham extended activities of daily living scale in patients undergoing total hip replacement. Disabil Rehabil 2002;24:371-7.

12 Goldberg DP, Hillier VF. A scaled version of the general health questionnaire. Psychol Med 1979;9:139-45.

13 Stuck AE, Siu AL, Wieland GD, Adams J, Rubenstein LZ. Comprehensive geriatric assessment: a meta-analysis of controlled trials. Lancet 1993:342:1032-6.

14 Shepperd S, Iliffe S. Hospital at home versus in-patient hospital care Cochrane Database Syst Rev 2001;(2):CD000356.

(Accepted 15 May 2005)

doi $10.1136 /$ bmj.38498.387569.8F

\title{
Commentary: Intermediate care: policy before evidence
}

\section{Norman J Vetter}

Cardiff University School of Medicine, Cardiff CF14 4XL

Norman J Vetter reader in public health

njvetter@ hotmail.com
Intermediate care had the characteristics of much new national policy when it was launched; it lacked definition, had no evidence for its effectiveness, and was aimed at solving a problem that it was unlikely to impact on-in this case overcrowding in hospitals. It is therefore good to see new evidence on the effectiveness of a service that fits under the umbrella term "intermediate care" compared with care in a district general hospital department for the care of elderly people, as reported by Green et al. ${ }^{1}$

The relation between older people and hospitals is a complex one. A suspicion among several eminent commentators is that ageism is still endemic in the NHS, keeping older people out of the bright sparkling general hospitals because they overstay their welcome. ${ }^{2}$ A further suspicion is that the National Service Framework for older people is complicit in this, with its emphasis on an extra 5000 intermediate care beds, with no real definition or evidence for such an approach or for the number chosen (it would seem to be a heavy dose of digit preference). This suspicion is added to by the suggestion in the National Service Framework that acute admission rates for people aged over 75 should rise less than $2 \%$ per annum, again with no evidence to suggest that this percentage will match clinical need or that likely geographical variations should be taken into account. A fixed percentage seems especially odd in a country that has a successfully ageing population. Most geriatricians would regard 75 as quite young.

Work on methods of diverting older people into intermediate care straight from home has not proved successful so far using a non-randomised cohort approach. ${ }^{3}$ A systematic review of a nurse led intermediate care facility for post-acute rehabilitation, however, suggested that this is effective, although the authors urge caution as this may be due to an increased length of stay in the nurse unit. They also make the point that the safety of the approach has not been fully proved. ${ }^{4}$ An economic evaluation using participants from a randomised trial has shown that such a nurse led unit was more expensive than a traditional approach. $^{5}$

Green et al show that another approach-a single community hospital, in Bradford-gave better results in one variable, of many, compared with a hospital based unit for elderly people. The organisation of the study had lots of difficulties, but such health services research is always beset by such issues. In an area where resources are scarce, people are loath to allow their favourite patient groups to be entered into the lottery of a randomised trial. Many of us have had similar experiences. So the study group was unusual by the time randomisation took place. This, and the small proportion of positive outcomes, compared with the number measured, makes the work difficult to generalise elsewhere.

Overall, the paper does a little more to clothe the Emperor of intermediate care, but he is still not really fit to be seen out in public.

Competing interests: None declared.

1 Green J, Young J, Forster A, Mallinder K, Bogle S, Lowson K, et al. Effect of locality based community hospital care on independence in older people needing rehabilitation: randomised controlled trial. $B M$ 2005;331:317-20.

2 Grimley EJ, Tallis RC. A new beginning for care for elderly people? $B M J$ 2001:322:807-8.

Walker L, Jamrozik K. Effectiveness of screening for risk of medical emergencies in the elderly. Age Ageing 2005;34:238-42.

Griffiths P, Edwards M, Forbes A, Harris R. Post-acute intermediate care in nursing-led units: a systematic review of effectiveness. Int I Nurs Stud $2005 \cdot 42 \cdot 107-16$

5 Walsh B, Steiner A, Pickering RM, Ward-Basu J. Economic evaluation of nurse led intermediate care versus standard care for post-acute medical patients: cost minimisation analysis of data from a randomised controlled trial. BMJ 2005;330:699

doi $10.1136 /$ bmj.38524.543137.7C 